\title{
Publisher Correction: Genome-wide association of polycystic ovary syndrome implicates alterations in gonadotropin secretion in European ancestry populations
}

M. Geoffrey Hayes, Margrit Urbanek, David A. Ehrmann, Loren L. Armstrong, Ji Young Lee, Ryan Sisk, Tugce Karaderi, Thomas M. Barber, Mark I. McCarthy, Stephen Franks, Cecilia M. Lindgren, Corrine K. Welt, Evanthia Diamanti-Kandarakis, Dimitrios Panidis, Mark O. Goodarzi, Ricardo Azziz, Yi Zhang, Roland G. James, Michael Olivier, Ahmed H. Kissebah, Reproductive Medicine Network, Elisabet Stener-Victorin, Richard S. Legro \& Andrea Dunaif

Correction to: Nature Communications https://doi.org/10.1038/ncomms8502, published online 18 August 2015.

The original version of the Supplementary Data associated with this Article duplicated Supplementary Data 10 for both Supplementary Data 9 and Supplementary Data 10. The correct version of Supplementary Data 9 is provided below.

\section{Additional information}

Supplementary information is available for this paper at https://doi.org/10.1038/s41467-020-15793-w.

\footnotetext{
(c) (i) Open Access This article is licensed under a Creative Commons Attribution 4.0 International License, which permits use, sharing, adaptation, distribution and reproduction in any medium or format, as long as you give appropriate credit to the original author(s) and the source, provide a link to the Creative Commons license, and indicate if changes were made. The images or other third party material in this article are included in the article's Creative Commons license, unless indicated otherwise in a credit

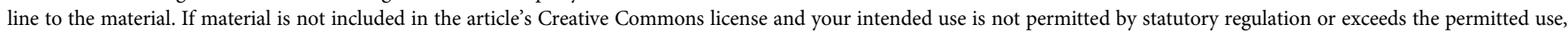
you will need to obtain permission directly from the copyright holder. To view a copy of this license, visit http://creativecommons.org/licenses/by/4.0/.
}

(c) The Author(s) 2020 